\title{
Analisis Faktor-faktor yang Mempengaruhi Perilaku Konsumen dalam Pengambilan Keputusan Pembelian White Coffee
}

\section{Analysis of Factors that Influence Consumers Behaviour in Making White Coffe Purchasing Decission}

Umar Khasan

Laboratorium Komputasi Program Studi Agribisnis Universitas Trunojoyo Madura

DOI: https://doi.org/10.32781/cakrawala.v12i2.271

\begin{tabular}{l|l}
\hline ARTICLE INFO & $\begin{array}{l}\text { Abstrak: } \\
\text { Tujuan penelitian ini adalah menganalisis faktor-faktor yang mempengaruhi } \\
\text { Pembelian produk White Coffe. Penelitian ini dilaksanakan di Hypermart } \\
\text { White Cofe }\end{array}$ \\
\hline Consumen Preference \\
$\begin{array}{l}\text { Bangkalan. Sampel diambil dengan metode Accidental Sampling. Data } \\
\text { dianalisis dengan metode diskriptif kualitatif. Hasil penelitian menunjukan } \\
\text { bahwa faktor yang mempengaruhi keputusan pembelian White Coffe adalah } \\
\text { budaya, tingkat pendidikan, usia, dan jenis kelamin.. } \\
\text { Abstract: } \\
\text { Received : Oktober } 2018 \\
\text { Accepted: December } 2018 \\
\text { Coffee. Research was carried out in Hypermart Bangkalan. Sample was taken } \\
\text { by accidentl sampling method. Data were analyzed by qualitative diskriptif. } \\
\text { The result of factors affect the purchase decision of White Coffee are culture, } \\
\text { age and Sex. }\end{array}$ \\
\hline
\end{tabular}

\section{Pendahuluan}

Kopi sudah menjadi produk unggulan dalam sub sektor perkebunan selain karet, kelapa sawit, teh, kina dan tebu (Arifin, 2004). Luas areal kopi di Indonesia sampai dengan tahun 2016 rata-rata meningkat sebesar $1,61 \%$ per tahun atau bertambah 14.212 ha per tahun, sedangkan ratarata produktivitas kopi di Indonesia baru mencapai $722 \mathrm{~kg} / \mathrm{ha}$ atau terjadi penurun dari tahun sebelumnya sebesar $0.41 \%$ (Kementan, 2016).

Kopi merupakan tanaman perkebunan berorientasi ekspor. Sejak tahun 2003 pertumbuhan volume ekspor kopi mencapai $21,26 \%$ per tahun atau sebesar 471,240 ton per tahun. Nilai devisa yang disumbangkan kopi adalah 4..521,5 juta US\$ dan terus mengalami peningkatan tiap tahunnya (Kementan, 2016). Selain sebagai komoditas ekspor, kopi juga menjadi komoditas yang banyak dikonsumsi di dalam negeri. Minuman yang menyegarkan dan non alkohol ini sudah dikenal kalangan masyarakat Indonesia dari sebagai bentuk karya leluhur.

Masyarakat Indonesia dalam mengkonsumsi kopi dalam bentuk olahan. Dikarenakan tuntutan dari masyarakat yang menginginkan produk instant, akan tetapi memiliki nilai tersendiri dalam memenuhi kebutuhan konsumen (Mizfar dan Sinaga, 2015). Kopi dalam bentuk olahan yang sering dijumpai di Indonesia adalah kopi

Cite this as:

Khasan, U. (2018). Analisis Faktor-faktor yang Mempengaruhi Perilaku Konsumen dalam Pengambilan Keputusan Pembelian White Coffee. Cakrawala, 12(2). 157-61 https://doi.org/10.32781/cakrawala.v12i2.271.

Corresponding author:
Address $\quad:$ Perum Taloon Permai Blok B 10 Kamal
Email $\quad:$ umar.khasan@trunojoyo.ac.id
Phone $\quad: 085232044703$
(C) 2018 Badan Penelitian dan Pengembangan Provinsi Jawa Timur p-ISSN 1978-0354 | e-ISSN 2622-013X 
bubuk dan kopi sachet. Berbagai jenis kopi sachet saat ini mulai bermunculan, mulai dari Kapal Api, TOP Coffe, Kopi ABC, Kopiko bahkan muncul jenis kopi dengan varians White Coffe.

Munculnya White Coffee instan pertama oleh PT Javaprima Abadi Semarang dengan merek Luwak White Coffee menyita perhatian produsen kopi sehingga muncul produk yang serupa seperti Kopiko White Coffee, TOP White Coffee, Kapal Api White Coffee, dan ABC White Coffee. Bagi produsen White Coffee kondisi ini sangat tidak menguntungkan dan mereka membutuhkan informasi tentang peta image konsumen terhadap produk White Coffee yang ada di pasar. Penelitian ini bertujuan untuk menganalisis faktorfaktor yang mempengaruhi pengambilan keputusan pembelian White Coffe.

\section{Metode Penelitian \\ Lokasi Penelitian}

Penelitian ini dilakukan secara purposive di Hypermart Bangkalan dengan pertimbangan salah satu pusat perbelanjaan terbesar di Bangkalan sehingga menjadi pasar potensial bagi White Coffee dan lima merek kopi yang akan dianalisis terdapat pada lokasi penelitian.

\section{Metode Pengambilan Data/Sampel}

Sampel diambil dengan menggunakan teknik Accidental Sampling, sebanyak 40 orang (Sugiyono, 2009). Analisis faktorfaktor yang mempengaruhi pengambilan keputusan pembelian White Coffee dianalisis secara deskriptif kualitatif.

\section{Hasil dan Pembahasan}

Keputusan pembelian merupakan tahap akhir yang dilakukan oleh konsumen dalam melakukan proses pembelian terhadap produk White Coffee (Engel et al.,1994). Dalam proses pengambilan keputusan konsumen terhadap pembelian White Coffee dapat dipengaruhi oleh beberapa faktor yaitu budaya, pendapatan, tingkat pendidikan, usia dan jenis kelamin (Marbun, 2014; Mizfar dan Sinaga, 2015; Darmawan dkk., 2016).

\section{Budaya}

Budaya berpengaruh terhadap keputusan konsumen dalam pembelian White Coffee sebesar 38\% (Gambar 1). Hal serupa dengan penelitian Sumarwan (2004), bahwa budaya adalah segala nilai, pemikiran yang dapat berpengaruh terhadap perilaku, sikap, kepercayaan dan kebiasaan seseorang dalam menentukan pilihan. Hal serupa menurut Marbun (2014), bahwa

Tabel 1. Faktor-faktor yang Mempengaruhi Pengambilan Keputusan Pembelian White Coffee

\begin{tabular}{|c|c|c|c|c|c|c|}
\hline \multirow{2}{*}{ Variabel } & \multicolumn{5}{|c|}{ Frekuensi } & \multirow{2}{*}{ Tota } \\
\hline & 1 & 2 & 3 & 4 & 5 & \\
\hline Budaya & 5 & 11 & 7 & 15 & 2 & 40 \\
\hline Pendapatan & 6 & 11 & 8 & 9 & 6 & 40 \\
\hline Tingkat Pendidikan & 7 & 10 & 9 & 11 & 3 & 40 \\
\hline Usia & 6 & 4 & 8 & 8 & 14 & 40 \\
\hline Jenis kelamin & 8 & 9 & 7 & 12 & 4 & 40 \\
\hline
\end{tabular}

Sumber: Data Primer Diolah, 2018

Keterangan:

1 : Sangat Tidak Mempengaruhi,

2 : Tidak Mempengaruhi,

3 : Cukup Mempengaruhi,

4 : Mempengaruhi, dan

5 : Sangat Mempengaruhi 
budaya berpengaruh terhadap keputusan pembelian.

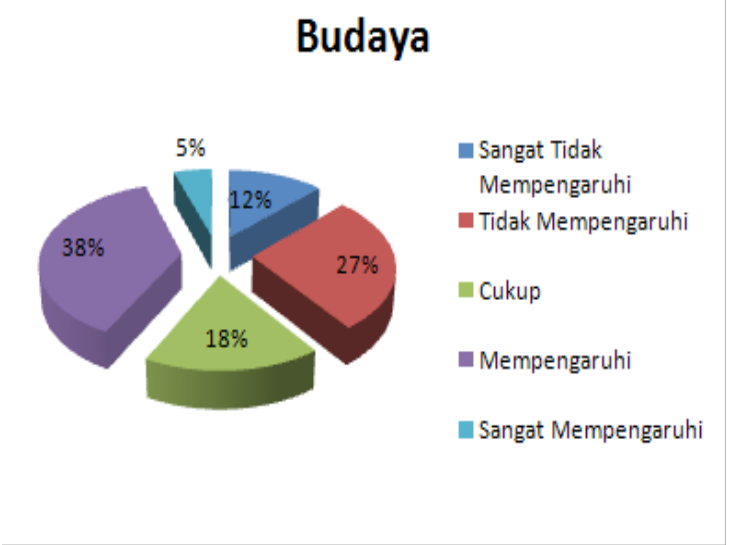

Gambar 1

Faktor Budaya terhadap Keputusan Pembelian White Coffe

Sumber: Data Primer Diolah, 2018

\section{Pendapatan}

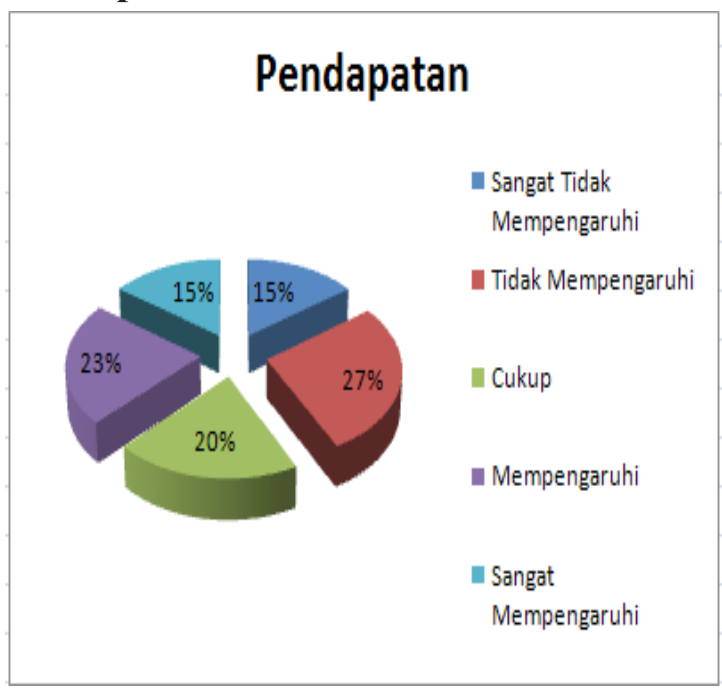

Gambar 2

Faktor Pendapatan terhadap Keputusan Pembelian White Coffe

Sumber: Data Primer Diolah, 2018

Pendapatan tidak mempengaruhi pembelian White Coffee sebesar $27 \%$. Pendapatan tidak berpengaruh dalam pengambilan keputusan pembelian White Coffee dikarenakan harga White Coffee yang relatif murah sehingga konsumen tetap bisa mengkonsumsi (Gambar 2). Penelitian ini mendukung penelitian dari Mizfar dan Sinaga (2015), bahwa pendapatan tidak mempengaruhi konsumen dalam pembelian kopi instan dengan nilai. Mengkonsumsi kopi sudah menjadi kebiasaan sehingga menjadi salah satu kebutuhan yang menyebabkan selalu membeli meskipun pendapatan berkurang.

\section{Tingkat Pendidikan}

Semakin tinggi tingkat pendidikan konsumen maka semakin tinggi pula keputusan konsumen dalam menentukan pembelian White Coffee. Hubungan pendidikan dengan keputusan konsumen. Dari hasil penelitian diketahui bahwa tingkat pendidikan berpengaruh terhadap keputusan pembelian White Coffee sebesar 28\% (Gambar 3).

Menurut Mizfar dan Sinaga (2015), bahwa tingkat pendidikan berkorelasi positif dan signifikan pada $\alpha=5 \%$ terhadap perilaku konsumen. Hal ini ditunjukkan bahwa pendidikan mempunyai pengaruh terhadap keputusan konsumen sebesar 0.1983

\section{Usia}

Faktor selanjutnya yang mempengaruhi pengambilan keputusan dalam pembelian White Coffee adalah usia sebesar 35\%. Konsumen dalam membeli suatu produk akan bermacam-cama sepanjang umurnya. Hal ini dikarenakan tahapan siklus hidup, keadaan ekonomi, pekerjaan, dan faktor kesehatan konsumen itu sendiri. Menurut Priyono (2006), bahwa usia antara 26-30 tahun berpengaruh terhadap pengambilan keputusan untuk mengunjungi kafe di kodya Surakarta.

\section{Jenis Kelamin}

Faktor yang mempengaruhi keputusan konsumen dalam pengambilan keputusan pembelian White Coffee selanjutnya adalah 


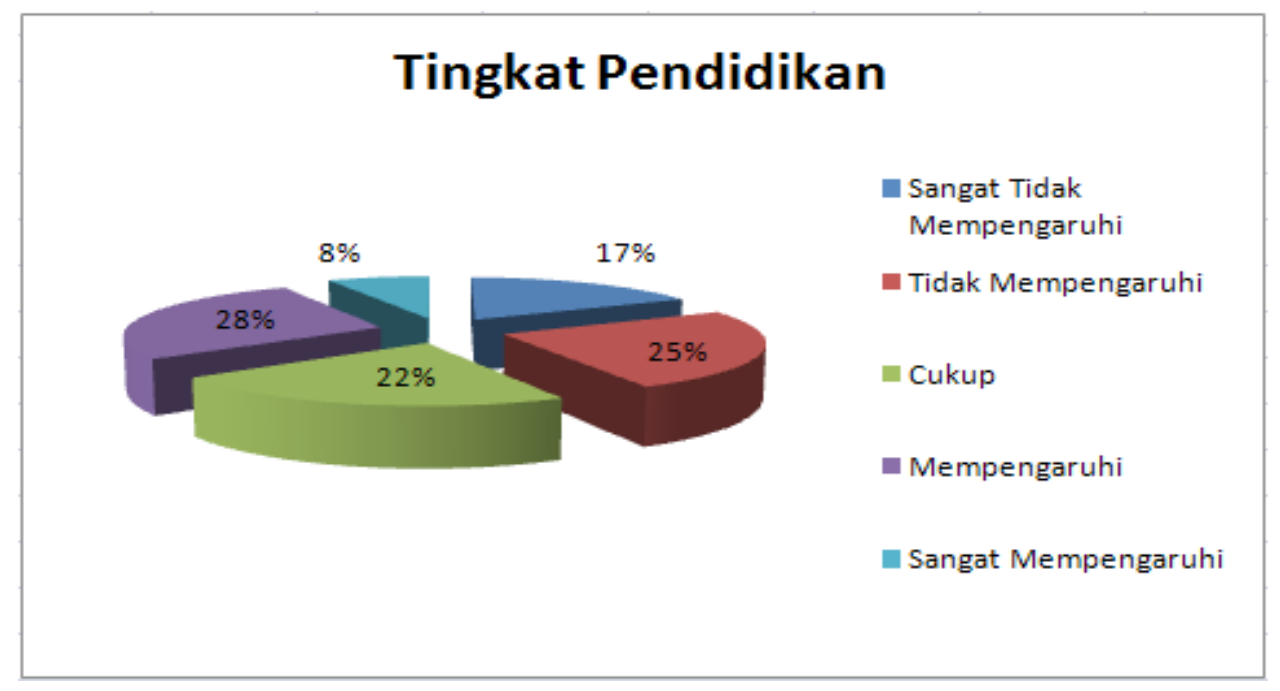

Gambar 3

Faktor Tingkat Pendidikan terhadap Keputusan Pembelian White Coffee (White Coffe)

Sumber: Data Primer Diolah, 2018

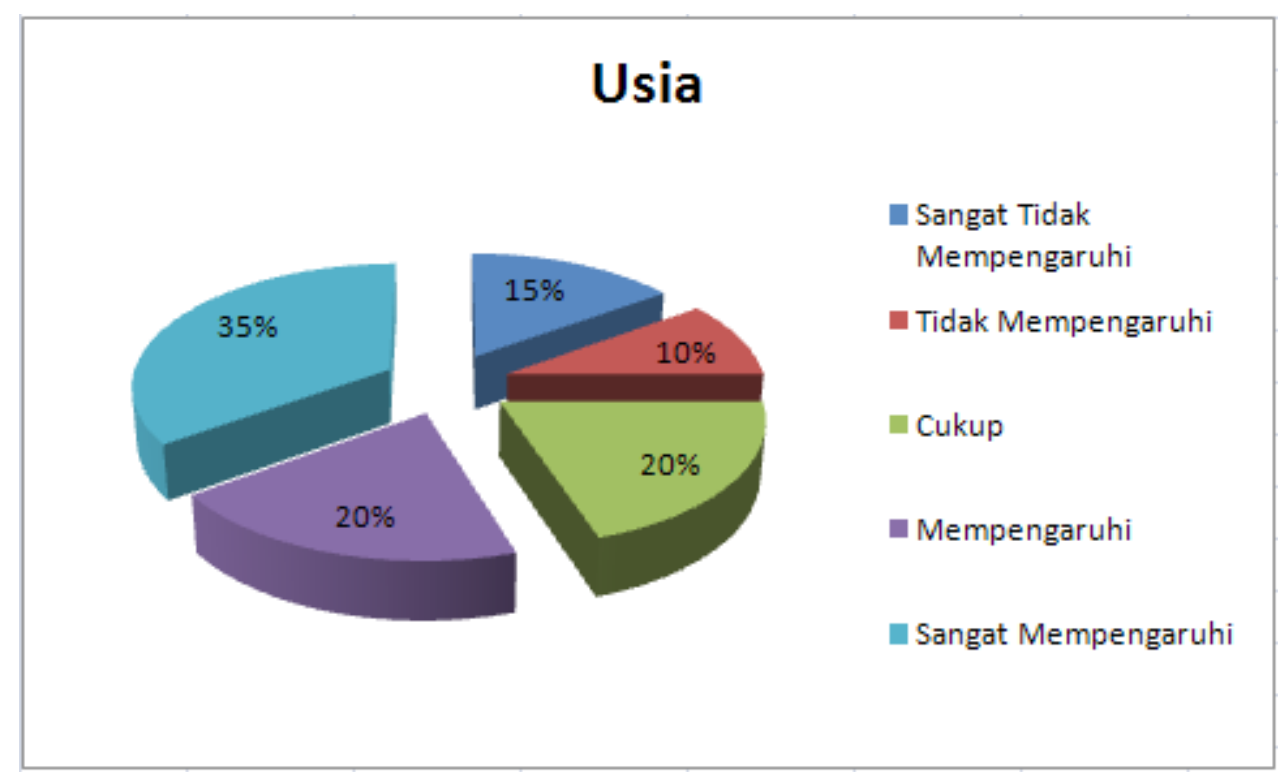

Gambar 4

Faktor Usia terhadap Keputusan Pembelian White Coffee

Sumber: Data Primer Diolah, 2018

jenis kelamin. Jenis kelamin berpengaruh terhadap keputusan konsumen dalam pengambilan keputusan pembelian sebesar 30\%. Menurut Mizfar dan Sinaga (2015), bahwa keputusan konsumen untuk membeli White Coffee-dipengaruhi oleh jenis kelamin sebesar 1.555 .

\section{Simpulan}

Faktor-faktor yang mempengaruhi pengambilan keputusan pembelian White Coffe adalah budaya, tingkat pendidikan, usia, dan jenis kelamin. sedangkan faktor pendapatan tidak mempengaruhi pengambilan keputusan pembelian 
White Coffe sebesar. Pendapatan tidak berpengaruh dalam pengambilan keputusan pembelian White Coffee dikarenakan harga White Coffee yang relatif murah sehingga konsumen tetap bisa mengkonsumsi.

\section{Daftar Pustaka}

Arifin, Bustanul. (2004). Analisis Pertanian Indonesia. Penerbit Buku Kompas. Jakarta.

Darmawan, H. Kasimin, S. Marsudi, E. (2016). Analisis Korelasi Antara Karakteristik Konsumen dengan Karakteristik Warung Kopi di Kota Banda Aceh. Jurnal Ilmiah Mahasiswa Pertanian Unsyiah, 1(1). 410-417.

Engel, J.F, Roger D. Blackwell, Paul W. Miniard. (1994). Perilaku Konsumen. Edisi ke-6 jilid I (terjemahan). Binarupa Aksara. Jakarta.

Kementerian Pertanian. (2016). Outlook Kopi Komoditas Pertanian Subsektor Perkebunan. Pusat Data dan Sistem Informasi Pertanian Sekretariat Jenderal - Kementerian Pertanian.

Marbun, I. I. (2014). Analisis Faktorfaktor yang Mempengaruhi Perilaku Konsumen Kopi Luwak Bermerek di Kota Medan. Skripsi. Program Studi Agribisnis Fakultas Pertanian Universitas Sumatera Utara Medan.

Mizwar, F. dan Sinaga, A. (2015). Analisis Faktor-faktor yang Mempengaruhi Perilaku Konsumen dalam Pengambilan Keputusan Pembelian Kopi Instan. SEPA, 11(2). 175-180.
Priyono, E. (2006). Analisis Faktor-faktor yang Mempengaruhi Konsumen dalam Memilih Kafe di Kota Surakarta. BENEFIT, 10(1). 49-65.

Sumarwan, U. (2004). Perilaku Konsumen: Teori dan Penerapannya dalam Pemasaran. Ghalia Indonesia. Bogor.

Sugiyono. (2009). Metode Penelitian Bisnis. Alfabeta : Bandung. 